\title{
LETTERS
}

\section{Federal leadership needed to realize national data set for cardiovascular care}

Drs. Morin and Flegel, in their recent editorial on the desirability of a national health care data network, ${ }^{1}$ make a strong and valid case for a systematic and organized initiative to use the rich and multifaceted data on health care encounters, processes and outcomes to monitor, evaluate and improve health care.

The Canadian Cardiovascular Society, through its Quality Project, is committed to precisely this goal. Following a detailed process to derive data definitions and quality indicators for a variety of cardiac disorders and procedures, the Canadian Cardiovascular Society and its partners (including the Canadian Institute for Health Information, provincial agencies, hospitals and caregivers) has spearheaded Quality Reports in aortic transcatheter valve procedures, percutaneous cardiac interventions and cardiac surgery.

To fully realize the potential for a national health care data set, it will be required for provincial ministries of health; provincial agencies that collect health care information; regional and national agencies with a mandate to collect health information; hospitals; and the medical community to work together to permit and encourage data sharing, data transfer and transparency in reporting while respecting the important need for security and confidentiality of data.

We believe that support from the federal government of Canada is critical to the success of this process, and to enabling access to high-quality care, portability and health equity for patients with cardiovascular disease across Canada.

We cannot improve or manage what we do not measure. It is time to advocate strongly for what might become a missed opportunity.

\section{Paul Dorian MDCM MSc}

Chair, Canadian Cardiovascular Society Quality Project (on behalf of the Quality Project Steering Committee); Department Division Director, Cardiology, Department of Medicine, University of Toronto, Toronto, Ont.

\section{Catherine Kells MD}

President, Canadian Cardiovascular Society; Professor, Division of Cardiology, Department of Medicine, Dalhousie University, Halifax, NS

Cite as: CMAJ 2017 October 16;189:E1294. doi: $10.1503 / \mathrm{cmaj} .733412$

\section{Reference}

1. Morin SN, Flegel K. A national health care data network is overdue. CMAJ 2017;189:E951.

Competing interests: None declared. 